Review

\title{
Nonhuman Primate Models of Chikungunya Virus Infection and Disease (CHIKV NHP Model)
}

\author{
Rebecca Broeckel ${ }^{1, \dagger}$, Nicole Haese ${ }^{1, \dagger}$, Ilhem Messaoudi ${ }^{2}$ and Daniel N. Streblow ${ }^{1, *}$ \\ 1 Vaccine \& Gene Therapy Institute, Oregon Health \& Science University, 505 NW 185th Ave, \\ Beaverton, OR 97006, USA; E-Mails: broecker@ohsu.edu (R.B.); haese@ohsu.edu (N.H.) \\ 2 Division of Biomedical Sciences, School of Medicine, University of California-Riverside, \\ Riverside, CA 92521, USA; E-Mail: ilhem.messaoudi@ucr.edu \\ $\dagger$ These authors contributed equally to this work. \\ * Author to whom correspondence should be addressed; E-Mail: streblow@ohsu.edu; \\ Tel.: +1-503-418-2772; Fax: +1-503-418-2719.
}

Academic Editor: Thomas E. "Tem" Morrison

Received: 17 August 2015 / Accepted: 9 September 2015 / Published: 16 September 2015

\begin{abstract}
Chikungunya virus (CHIKV) is a positive-sense RNA virus transmitted by Aedes mosquitoes. CHIKV is a reemerging Alphavirus that causes acute febrile illness and severe and debilitating polyarthralgia of the peripheral joints. Huge epidemics and the rapid spread of CHIKV seen in India and the Indian Ocean region established CHIKV as a global health concern. This concern was further solidified by the recent incursion of the virus into the Western hemisphere, a region without pre-existing immunity. Nonhuman primates (NHPs) serve as excellent animal models for understanding CHIKV pathogenesis and pre-clinical assessment of vaccines and therapeutics. NHPs present advantages over rodent models because they are a natural amplification host for CHIKV and they share significant genetic and physiological homology with humans. CHIKV infection in NHPs results in acute fever, rash, viremia and production of type I interferon. NHPs develop CHIKV-specific B and T-cells, generating neutralizing antibodies and $\mathrm{CHIKV}$-specific $\mathrm{CD}^{+}$and $\mathrm{CD} 8^{+} \mathrm{T}$-cells. CHIKV establishes a persistent infection in NHPs, particularly in cynomolgus macaques, because infectious virus could be recovered from spleen, liver, and muscle as late as 44 days post infection. NHPs are valuable models that are useful in preclinical testing of vaccines and therapeutics and uncovering the details of CHIKV pathogenesis.
\end{abstract}


Keywords: chikungunya virus; nonhuman primate; polyarthritis; pathogenesis; immunity

\section{Introduction}

Chikungunya virus (CHIKV) is a mosquito-transmitted RNA virus that causes acute febrile illness and severe debilitating joint pain. CHIKV belongs to the Semliki Forest virus clade of Old World Alphaviruses [1,2]. CHIKV historically caused sporadic outbreaks in Africa and Southeast Asia [3]. Globalization and ease of overseas travel have increased risk of spread of CHIKV to other regions without preexisting immunity and competent Aedes mosquito vectors. In densely populated regions of susceptible humans it is estimated that the infection rate is between $30 \%-75 \%$ [4-6]. The 2004-2007, endemic in the Indian Ocean region and India demonstrated the potential of CHIKV to rapidly spread and establish itself in new geographical regions. In December of 2013, CHIKV achieved autochthonous transmission in the Western hemisphere in the Caribbean Islands [7,8] and subsequently became established in Central and South America, Mexico, and the mainland United States (Florida) [9]. According to the Centers for Disease Control and Prevention (CDC), over 1.5 million cases have occurred in the Western hemisphere [10]. Risk of spread could be reduced with increased vector control such as removal of mosquito breeding sites, mosquito repellent, and community awareness.

CHIKV has a $12 \mathrm{~kb}$ positive-sense single stranded RNA genome consisting of four nonstructural proteins (nsp1-4) and five structural proteins (capsid, E3, E2, 6k, and E1) [11]. CHIKV is an enveloped virus studded with 80 trimers of E1/E2 dimers [12]. While the cellular receptor for the virus is unknown, CHIKV enters cells via clathrin-mediated endocytosis and the capsid containing genomic RNA is released into the cytoplasm [13]. The nonstructural proteins are translated from the genomic RNA and together form the NSP protein complex that includes the viral RNA-dependent RNA polymerase which is necessary for minus and plus strand genomic RNA replication [14]. The NSP complex also synthesizes the subgenomic RNA from minus-strand RNA that codes for the structural polyprotein. During translation of the structural polyprotein, the capsid autocatalytically cleaves itself, exposing an Nterminal ER localization signal $[15,16]$. The envelope proteins are folded in the endoplasmic reticulum (ER), and they undergo further processing and glycosylation in the ER and Golgi secretory network before being presented on the plasma membrane. The capsid complex assembles around the genomic RNA and interacts with the envelope proteins at the plasma membrane [17,18]. The virions bud and are released for the next round of infection.

The acute stage of CHIKV disease, in humans, is characterized by rash, high fever, headache, and arthralgia. These symptoms can appear within 3-7 days and typically last for two weeks. After a bite from an infected Aedes mosquito, the virus replicates locally in the skin and disseminates via the blood to peripheral joints, muscle, tendons, liver, and lymph nodes. Replication in these tissues results in inflammation, synovitis, and tenosynovitis causing intense pain in the joints, tendons, and muscles. The sub-acute phase of CHIKV or convalescent phase is associated with resolution of viremia, fever, and induction of CHIKV-specific T-cell and antibody immune responses. A significant portion of those infected will enter into the chronic phase of CHIKV disease, characterized by recurring polyarthritis, myalgia, and tenosynovitis [19,20], that can last for months to years post infection [19,21-25]. 
The prevailing hypothesis is that incomplete clearance of CHIKV from specific tissues leads to chronic infection. Persistent CHIKV may replicate at low levels in the joints and muscles, causing long-term arthritic pain and myalgia. Risk factors in developing persistent CHIKV associated rheumatic manifestations are increased age ( $>45$ years old), preexisting arthritis or joint disease, hypertension, and increased disease severity during the acute phase of disease [24]. Though considered a relatively benign disease, CHIKV can cause serious, even fatal disease in neonates, aged, and immunocompromised populations. Other underlying medical conditions such as diabetes, cardiovascular disease, neurological disorders, and chronic pulmonary diseases are risk factors for developing severe CHIKV disease [26]. Atypical symptoms include encephalitis, seizures, heart failure and arrhythmias, renal failure, skin lesions, and blindness [26-28]. There is documented evidence of perinatal mother-to-child transmission resulting in severe disease, including fever, rash, hemorrhagic disease, and seizures from La Reunion, an Indian Ocean Island where $30 \%-40 \%$ of the population was infected during the $2005-2006$ Indian Ocean Island epidemic [29].

CHIKV has natural cycles of reemergence that occur in patterns of several years to decades after previous epidemics [3,30]; the virus is thought to maintain itself in NHPs or other vertebrate reservoirs and is reintroduced to regions with susceptible populations lacking preexisting immunity to CHIKV. The transmission cycle from NHPs (or other vertebrate such as rodents) to humans using a mosquito vector is known as the zoonotic sylvatic transmission cycle. However, CHIKV does not require an animal intermediate. In densely populated areas CHIKV utilizes an urban transmission cycle involving only humans and mosquitoes. The most important mosquito vectors in urban transmission cycles are the anthropophilic species Aedes aegypti and Aedes albopictus. The zoonotic sylvatic transmission cycle is believed to occur in West and Central Africa involving forest-dwelling Aedes mosquitoes, NHPs, and other vertebrate reservoirs [31-34]. It is possible that a zoonotic sylvatic transmission cycle exists in Asia because of isolation of infectious virus from NHPs in Malaysia [35] and CHIKV-specific antibodies present in Asian NHPs [36,37]; however, the nature of the transmission cycle in Asia needs to be more thoroughly studied. Both humans and NHPs serve as amplification hosts for CHIKV, thus highlighting the importance of studying CHIKV in NHPs. Genetic analysis of several CHIKV isolates revealed that there are three distinct CHIKV lineages: the Asian clade, West African clade, and East/Central/South African (ECSA) clade [38]. Sequence analysis showed that CHIKV isolates from the Indian Ocean outbreak were of the ECSA lineage. Importantly, CHIKV isolates from the Indian Ocean outbreak contained a point mutation in E1 (A226V) that increased its infectivity in Aedes albopictus mosquitoes [39-41]. The CHIKV-LR isolates were sampled during the Indian Ocean outbreak and contain this point mutation. Other CHIKV isolates commonly used in NHP studies include the Senegal isolate CHIKV-37997 from the West African clade and the ECSA isolate CHIKV-DHS-4263 obtained from a traveler in India during the Indian Ocean Island outbreak [42]. The circulating strain in the Caribbean stems from the Asian lineage, but the Caribbean isolates have not been used in any reported NHP studies [43]. 


\section{Animal Models of CHIKV}

\subsection{Mouse Models of CHIKV Infection and Disease}

There are many different animal models that have been used for studying CHIKV pathogenesis, mostly involving different laboratory mouse strains. Of note, neonatal mice and mice that lack the type I interferon receptor are highly susceptible to CHIKV infection, indicating the importance of type I interferon in controlling virus infection [44]. $\mathrm{Rag} 1^{-/}$mice, which are deficient in mature $\mathrm{B}$ and T-cells, develop a persistent CHIKV infection in which infectious virus can be recovered from tissues and serum for the lifetime of the mouse $[45,46]$. Transfer of immune sera into the Rag $1^{-/-}$mice results in a transient reduction of infectious virus in the serum [45] that returns after a few weeks [46]. This demonstrates that though antibodies can clear virus in the serum for a short time, they are not sufficient for complete viral clearance. The direct role for T-cells still remain elusive, but it has been shown that $\mathrm{CD}^{+} \mathrm{T}$-cells may play a role in joint swelling [47]. Infection of young and adult C57BL/6 mice with CHIKV in the footpad can recapitulate the arthritis and myositis symptoms seen in humans [48,49]. In addition, CHIKV RNA can be detected in this mouse model for several weeks post infection, providing evidence for CHIKV persistence [45,48]. However, unlike the polyarthritis that occurs during human CHIKV infections, arthritis in mice is usually limited to the infected ipsilateral joint. There are several mouse models available for understanding different aspects of CHIKV pathogenesis and immunity; however, uncovering the details of CHIKV infection in NHPs may be more relevant to human infection and disease due to immunological and physiological similarities. Thus, the NHP model of CHIKV infection more accurately predicts the human outcomes of antiviral therapeutics and vaccines.

\subsection{NHP Models of CHIKV Infection}

The first CHIKV NHP experiments were performed in 1953 in the Newala district of Tanzania. R.W. Ross demonstrated that rhesus macaques developed neutralizing antibodies to inoculations with viremic human sera [50]. Other early studies in rhesus macaques showed development of viremia 2-4 days post infection (dpi), production of neutralizing antibodies, and protection from reinfection [51]. Three recent studies have provided a more detailed picture of CHIKV pathogenesis using the following animal models: adult (6-13 years old) and aged rhesus macaques ( $>17$ years old) [52]; cynomolgus macaques [53]; and pregnant rhesus macaques [42].

\subsubsection{Acute Stage of CHKV Infection in NHP}

The acute stage of CHIKV infection in NHPs has similarities to acute CHIKV infection in humans. In humans, viremia lasts an average of 4-6 days, but can last up to 12 days post-onset of illness, with viremia reaching between $10^{5}$ to $10^{12} \mathrm{pfu} / \mathrm{mL}$ [54-58]. Development of viremia in CHIKV-infected NHPs has been studied since the 1960s [42,51,53,59-61]. CHIKV has been experimentally administered to NHP by a variety of means including subcutaneous, intravenous, and intramuscular injections. However, it is unclear how the specific routes of infection and reliance on mosquito-specific delivery mechanisms and/or saliva effect CHIKV transmission and subsequently pathogenesis. Elegant intravital microscopy analysis of feeding patterns of Anopheles mosquitoes demonstrated the impact of mosquito 
age and malaria infection on increasing feeding behavior and pathogen transmission, which highlights the importance of determining pathogen: vector interactions and their role in mosquito transmission [62]. In the early CHIKV macaque studies, monkeys infected with either CHIKV-African E-103 or CHIKV-Asian BAH-306 developed viremia that lasted 4-5 days with peak viremia levels occurring 2-4 dpi, reaching $10^{4}-10^{6} \mathrm{pfu} / \mathrm{mL}$ [51]. Results from more recent studies utilizing rhesus macaques inoculated with either CHIKV-LR or CHIKV-37997 at varying doses $\left(10^{7}, 10^{8}\right.$, or $\left.10^{9} \mathrm{pfu}\right)$ reported that regardless of inoculating dose, animals were viremic by 2 dpi with resolution around 5 dpi. Animals infected with CHIKV-LR had slightly higher peak viremias compared to CHIKV-37997 infected animals $\left(5.7 \times 10^{6}\right.$ vs. $5.9 \times 10^{5}$ vRNA/10 $\mu \mathrm{L}$ plasma, respectively) [59]. Cynomolgus macaques infected with CHIKV-LR at the same dose range also developed peak viremia by 2 dpi with higher viral loads than those observed in rhesus $\left(5 \times 10^{9} \mathrm{vRNA} / \mathrm{mL}\right.$ plasma) [53]. In contrast to rhesus, the higher the inoculation dose the sooner viremia peaked and the higher peak viremia levels occurred in cynomolgus macaques. Pregnant rhesus macaques infected with CHIKV-37997 or DHS-4263 developed viremia lasting from 1-5 dpi, peaking at 2-3 dpi. Maximum viral load in pregnant rhesus macaques infected with CHIKV-DHS-4263 was significantly higher compared to infection with CHIKV-37997 [42]. These studies show that infection with specific CHIKV isolates such as CHIKV-LR or CHIKV-DHS-4263 results in higher peak viremia compared to $\mathrm{CHIKV}-37997$, and that cynomolgus macaques are generally more susceptible to development of high titer viremia compared to rhesus macaques.

As described for humans, clinical presentation of acute CHIKV infection in NHPs included high fever at 1-2 dpi that persisted for 2-7 days in cynomolgus, 3-7 days in rhesus, and 17-19 days in pregnant rhesus macaques; fever coincided with rash during the first week of infection $[42,53,59]$. In cynomolgus macaques, severity of symptoms correlated with CHIKV dose. Those animals receiving a high dose of CHIKV-LR $\left(10^{7}-10^{8} \mathrm{pfu}\right)$ exhibited joint swelling of the wrist and ankle in addition to viremia, fever and rash. A moderate dose $\left(10^{2}-10^{6} \mathrm{pfu}\right)$ caused only viremia, fever and rash, while a low dose $\left(10^{1} \mathrm{pfu}\right)$ caused no clinical symptoms except for viremia in some animals.

Leukopenia has been described following CHIKV infection of both cynomolgus macaques and pregnant rhesus macaques. Additional alterations in the hemogram included monocytopenia, lymphopenia, granulocytosis, and thromobocytopenia. Changes in blood cell numbers correlated with viremia, with the biggest decrease occurring during peak viremia, 2-4 dpi, followed by levels returning to normal by $10-15$ dpi. Both lymphocyte and neutrophil counts were significantly decreased in pregnant rhesus macaques at the time of peak viremia (Table 1) [42]. Similar patterns have also been observed during outbreaks of CHIKV in humans $[3,19,42]$. In a retrospective study of patients infected during the La Reunion outbreak in 2005, lymphopenia was the most common laboratory abnormality, observed in $79 \%$ of patients, followed by moderate thrombocytopenia, which was detected in $43.9 \%$ of patients [23]. Results from these NHP studies, along with what has been reported during human infection, support the idea that during CHIKV infection at peak viremia, immune cells are recruited from the blood into the surrounding tissues to control viral loads and reduce dissemination. 


\subsubsection{CHIKV Tissue Dissemination in NHPs}

Dissemination of CHIKV from the site of infection to other tissues throughout the body occurs as early as 2 dpi in infected macaques [53]. Infection of cynomolgus macaques with an intermediate dose of CHIKV-LR $\left(10^{2}-10^{6} \mathrm{pfu}\right)$ resulted in virus dissemination to multiple tissues along with mononuclear cell infiltration in the liver and lymphoid tissues of infected animals. Viral RNA was quantified in tissue lysates from liver, lymph node, liver, joint, muscle, skin, brain, and spinal cord of infected cynomolgus macaques. The viral load in most tissues peaked by 6 dpi but remained detectable for longer periods of time in many tissues including lymphoid organs, liver, synovial and muscular tissues, and CSF [53]. In rhesus macaques at $7 \mathrm{dpi}$, CHIKV was detected in joints, musculoskeletal tissues, heart, lung, liver, kidney, and lymphoid tissues, demonstrating the ability of CHIKV to disseminate to various tissues in this macaque model [63]. Similar to human infections, persistence of CHIKV in the infected adult rhesus monkeys is much more limited when compared to cynomolgus macaques. However, CHIKV-LR persisted in the spleen of aged rhesus macaques [59]. In the pregnant rhesus macaque model viral RNA was detected in the spleen and lymph node at 21 dpi. Detection of virus in other tissues was dependent on the CHIKV strain used for infection [42].

Infection of cynomolgus macaques with CHIKV resulted in histological abnormalities detected primarily in the liver, lymph nodes, and spleen. In the spleen, an increase of mononuclear cell infiltrates into the red pulp was observed 6-97 dpi [53]. Lymph nodes of infected animals also showed increased infiltration of mononuclear cells, primarily into the cortex, which was associated with enlargement of the follicular region 32-44 dpi. In the liver, there were abnormally high levels of hepatocyte death mainly due to apoptosis, peaking at $6 \mathrm{dpi}$. At an intermediate dose, CHIKV did not cause any major abnormalities in muscle, synovial samples or central nervous tissues. Using a high dose of CHIKV-LR ( $\geq 10^{7} \mathrm{PFU}$ ) histological findings were detected starting at $5 \mathrm{dpi}$ and remained detectable until $186 \mathrm{dpi}$ in some tissues [53]. The liver, lymph nodes, and spleen presented with the same histological findings as the intermediate dose of CHIKV, but cell infiltration was detectable to 186 dpi [53]. In addition, there were also regions of muscle fiber isolated at $186 \mathrm{dpi}$ with areas of detectable necrosis, associated with monocyte and macrophage infiltrates [53].

The ability of CHIKV to cause neurological symptoms in humans has been reported since the 1960-1970s [64-68] and also observed during more recent outbreaks [26,69-71]. Cynomolgus macaques infected with the high dose of CHIKV-LR exhibited symptoms of meningoencephalitis. Analysis of cerebrospinal fluid (CSF) collected from animals with signs of encephalitis, revealed a large number of mononuclear cells at 4 dpi. Characterization of the individual cell populations in the CSF by flow cytometry revealed that the majority of the cells were lymphocytes $(67 \%)$ with a small monocytes/macrophages contribution (9\%) [53]. Neurological symptoms are most commonly manifested in neonates after mother-to-child transmission. The incidence rate of neurological manifestations in adults is much lower; during the recent La Reunion outbreak only $15 \%-25 \%$ of adults that required hospitalization due to CHIKV infection had neurological symptoms [72]. Recapitulating neurological symptoms of CHIKV infection using a relevant infectious animal model has proven difficult. Mother-to-child CHIKV transmission is a rare event, unless the mother is viremic at or near the time of childbirth, in which case transmission can be as high as 50\% [73]. CHIKV was not transmitted to the fetus of pregnant rhesus macaques by transplacental transmission because the fetal tissues and 
placenta were found to be negative for CHIKV [42]. However, this study was limited to animals at gestation days 121-132. Future pregnant rhesus macaque studies need to investigate vertical CHIKV transmission closer to the end of gestation to determine whether the rhesus macaque model mimics CHIKV vertical transmission observed in humans. Additional studies need to be performed in NHP models in order to understand the neurological manifestations following CHIKV infection.

\subsubsection{CHIKV Persistence in NHPs}

There is mounting evidence for CHIKV persistence in both humans and rhesus macaques. A proportion of people infected with CHIKV may have recurring arthralgia but it is not known whether CHIKV chronic joint pain is caused by low-level persistent CHIKV replication or whether acute CHIKV replication disrupts an inflammatory equilibrium that causes arthritic pain after infection has resolved. The first evidence of CHIKV persistence in nonhuman primates was shown in adult, immunocompetent cynomolgus macaques infected with CHIKV-LR, and infectious virus was recovered as late as 44 days post infection from spleen, liver, and muscle (Table 1) [53]. The authors also postulated that CD68 ${ }^{+}$ macrophages might be reservoirs of persistence in the spleen. Another group showed evidence of CHIKV persistence in the spleen and lymph nodes in pregnant rhesus macaques at 21 days post infection by RT-PCR, but no infectious virus was recovered [42]. In addition, they did not detect CHIKV in the fetal tissues or placenta. Our group detected CHIKV RNA at 35 dpi in the spleen of aged, but not adult rhesus macaques. When aged rhesus macaques were given $10^{9}$ pfu CHIKV-LR, CHIKV RNA was detected in the spleen $35 \mathrm{dpi}$; however this was not the case when aged rhesus macaques were given the same dosage of CHIKV-37997 [52], suggesting that CHIKV-LR may be more virulent than CHIKV-37997 in aged macaques. Regardless of the macaque model, the consensus is that CHIKV RNA can be detected long-term in the spleen. In addition, CHIKV infections may be more severe and more persistent in cynomolgus macaques compared to rhesus macaques.

Table 1. Stages of Chikungunya virus (CHIKV) infection in non-human primates (NHPs).

\begin{tabular}{|c|c|c|c|c|}
\hline & $\begin{array}{l}\text { (a) Acute Stage } \\
1-6 \mathrm{dpi}\end{array}$ & $\begin{array}{c}\text { (b) Convalescent Stage } \\
7-34 \text { dpi }\end{array}$ & $\begin{array}{l}\text { (c) Persistent } \\
\text { stage }>35 \text { dpi }\end{array}$ & Reference \\
\hline Symptoms & $\begin{array}{c}\text { Fever, rash, joint } \\
\text { swelling, } \\
\text { lymphopenia }\end{array}$ & $\begin{array}{l}\text { Resolution of fever and } \\
\text { lymphopenia } \\
\text { Rash and joint swelling } \\
\text { resolving }\end{array}$ & Not determined & {$[42,51,53,59,74]$} \\
\hline Virus Detection & $\begin{array}{l}\text { Virus detectable in } \\
\text { the blood, lymph } \\
\text { nodes, liver, and } \\
\text { spleen }\end{array}$ & $\begin{array}{l}\text { Virus detectable in the } \\
\text { liver, lymph nodes, } \\
\text { spleen, joints, muscles, } \\
\text { and organs }\end{array}$ & $\begin{array}{l}\text { Virus detectable } \\
\text { in the liver, } \\
\text { spleen, joint } \\
\text { synovial tissue, } \\
\text { and muscle }\end{array}$ & {$[42,51,53,59,61,74-77]$} \\
\hline
\end{tabular}


Table 1. Cont.

\begin{tabular}{|c|c|c|c|c|}
\hline & $\begin{array}{c}\text { (a) Acute Stage } \\
\text { 1-6 dpi }\end{array}$ & $\begin{array}{c}\text { (b) Convalescent Stage } \\
7-34 \mathrm{dpi} \\
\end{array}$ & $\begin{array}{l}\text { (c) Persistent } \\
\text { stage }>35 \text { dpi }\end{array}$ & Reference \\
\hline $\begin{array}{c}\text { Innate } \\
\text { Response }\end{array}$ & $\begin{array}{l}\text { Active monocyte and } \\
\mathrm{mDC} \text { in the blood }\end{array}$ & $\begin{array}{c}\text { Robust pDC, mDC, \& } \\
\text { monocytes/macrophages }\end{array}$ & Not determined & {$[33,34]$} \\
\hline $\begin{array}{l}\text { Cytokine and } \\
\text { Chemokine } \\
\text { Production }\end{array}$ & $\begin{array}{c}\text { Increased IFN- } \alpha / \beta \& \\
\gamma, \text { IL-6, TNF- } \alpha, \text { IL- } \\
15, \\
\text { IL-1Ra, IL-2, CCL- } \\
2, \text { CCL-3, CCL-4, \& } \\
\text { VEGF }\end{array}$ & $\begin{array}{l}\text { Increased levels of IFN- } \\
\gamma, \text { TNF- } \alpha, \text { IL-2, CCL-2, } \\
\text { CCL-3, \& CCL-4 }\end{array}$ & Not determined & {$[42,53,59]$} \\
\hline $\begin{array}{l}\text { Virus-Specific } \\
\text { Immunity }\end{array}$ & $\begin{array}{l}\text { Virus-specific } \\
\text { immunity is } \\
\text { developing }\end{array}$ & $\begin{array}{c}\text { T-Cell Response: } \\
\text { Virus-specific CD4 }{ }^{+} \text {and } \\
\mathrm{CD}^{+}(\mathrm{EM} \text { and } \mathrm{CM}) \\
\text { B-Cell Response: } \\
\text { Virus-specific IgM \& } \\
\text { IgG }\end{array}$ & $\begin{array}{l}\frac{\text { T-Cell Response: }}{\text { Not determined }} \\
\text { B-Cell } \\
\text { Response: } \\
\text { Virus-specific } \\
\text { IgG }\end{array}$ & {$[42,51,53,59,61,78]$} \\
\hline
\end{tabular}

(a) During the acute stage of infection (1-6 dpi) CHIKV infection of NHPs results in viremia lasting an average of 4-5 days, fever, rash, and joint swelling. A reduction in numerous cell populations of the blood results in monocytopenia, lymphopenia, granulocytosis, and thromobocytopenia. The innate immune response is also initiated during the acute stage, supported by evidence of an increase in the number of monocytes and mDCs in the peripheral blood. Effectors of the type 1 IFN response are detected early in the acute stage, along with other proinflammatory cytokines/chemokines. (b) The convalescent stage of infection (7-34 dpi) is marked by dissemination of the virus from the blood to other organs of the body including the liver, lymph nodes, spleen, joints, muscles, and organs. The innate immune response continues, and the adaptive immune response is initiated during this stage of infection, including $\mathrm{T}$ and B-cell responses, and the production of both IgM and IgG virus specific antibodies. (c) During the persistent stage of infection ( $>35$ dpi) in NHPs, virus remains detectable in the liver, spleen, joint synovial tissues, and muscle. CHIKV is capable of persisting within NHP CD68 ${ }^{+}$ macrophages of the spleen. Virus specific IgG antibody responses have also been detected during this stage.

\subsubsection{NHP Immune Responses Following CHIKV Infection}

Innate Immune Cell Activation in NHP

Research by our group reported a difference in both the monocyte and dendritic cell (DC) numbers after CHIKV infection between adult and aged rhesus macaques infected with CHIKV-LR or CHIKV-37997. The levels of plasmacytoid DCs (pDCs) and myeloid DCs (mDCs) increased at 14 dpi before returning to baseline levels following infection of adult rhesus macaques with CHIKV-LR. In contrast, adults infected with CHIKV-37997 had high blood pDC levels by 4 weeks post infection (wpi) and moderate $\mathrm{mDC}$ recruitment by 14 dpi. Aged animals infected with either strain showed reduced levels of pDCs in the blood and a late $\mathrm{mDC}$ recruitment at 4 wpi [59]. These data indicated that aged macaques have defective and delayed DC recruitment in the blood. Monocytes/macrophage numbers were increased only in adult animals, with a more dramatic increase reported in CHIKV-37997 infected animals compared to CHIKV-LR infected rhesus macaques [59]. Interestingly, beginning at 2 dpi the monocyte 
and $\mathrm{mDC}$ populations in the peripheral blood of CHIKV-LR infected rhesus macaques become highly activated demonstrating increased surface expression for CD169. The level of CD169 returns to baseline between 5-7 dpi suggesting that this level of activation is transient and reflects the level of viremia (Streblow: unpublished data [79]).

In the cynomolgus macaque model of CHIKV infection, macrophages were not only reported to traffic to lymphoid tissues, but also stained positive for CHIKV antigen. CHIKV antigen positive CD68 ${ }^{+}$ macrophages were also reported in the spleen and lymph nodes of CHIKV-LR infected cynomolgus macaques as early as 2 dpi until 3 months after infection [53]. Further analysis of spleen CD68 ${ }^{+}$ macrophages, utilizing in situ hybridization and immunohistochemistry, confirmed the presence of CHIKV genomes in macrophages at both 6 and 19 dpi [53].

Cytokine Response in CHIKV-infected NHP

A key component of the immune response against CHIKV is the production of cytokines and chemokines. In humans, the type 1 IFN response plays a key role in controlling the severity of CHIKV infections $[22,49,80]$. In the cynomolgus macaque model, IFN- $\alpha / \beta$ levels were increased $1-2$ dpi and then fell sharply at 4 dpi, following the same pattern as viremia [53]. In other studies with NHPs, specifically rhesus macaques, plasma levels of bioactive IFN were measured at 3 dpi through activation of interferon stimulated gene (ISG) expression. Fibroblasts treated with plasma from adult animals increased ISG expression but not when treated with serum from aged animals [59]. This demonstrated that aged animals are defective in their ability to produce functional type 1 IFNs.

The plasma levels of numerous other proinflammatory cytokines and chemokines also correlated with levels of peak viremia in cynomolgus macaques. IFN- $\alpha / \beta$, CCL2, IL- 6 , and IFN $\gamma$ levels increased sharply with viremia at $2 \mathrm{dpi}$ in the blood [53]. Other cytokines and chemokines that showed a significant increase over baseline levels during infection of cynomolgus macaques included TNF- $\alpha$, CCL-3 and CCL-4 [53]. A similar pattern of increase in cytokines with levels of viremia was reported for pregnant rhesus macaques infected with CHIKV. Peak levels of cytokines IL-2, IL-6, IL-15, IL-1Ra, and the chemokines CCL-2 and VEGF increased at 3 dpi and then decreased to baseline following the peak and decline of viremia (Table 1) [42].

\section{Antiviral T-Cells in CHIKV-Infected NHP}

The exact role that T-cells play in controlling CHIKV infection is still unclear. During human infection of CHIKV CD8 ${ }^{+}$T-cells seem to be preferentially activated during the first few days of infection followed by a switch to $\mathrm{CD}^{+} \mathrm{T}$-cells [22,81]. At later stages during chronic infection, the IFN- $\gamma$ T-cell response appears to be driven primarily by $\mathrm{CD} 8^{+} \mathrm{T}$-cells [22]. Mouse models have been key in demonstrating the importance of the adaptive immune response in controlling CHIKV infection [45]. CHIKV infection of laboratory mouse strains demonstrated the ability of both $\mathrm{CD} 4^{+}$and $\mathrm{CD} 8^{+} \mathrm{T}$-cells to infiltrate the joints $[48,82]$. According to these models, $\mathrm{CD} 4^{+} \mathrm{T}$-cells may have an important contributing role to the severity of inflammation and joint damage, recapitulating what is seen in autoimmune arthritis [47]. In rhesus macaques, $\mathrm{CD} 4^{+}$and $\mathrm{CD} 8^{+} \mathrm{T}$-cells proliferate normally: central memory (CM) T-cell subsets were generally detected prior to effector memory (EM) T-cell subsets. There was a diminished T-cell response in aged animals infected with CHIKV-37997 compared to adult 
animals infected with the same CHIKV strain [59]. Rhesus macaques infected with CHIKV develop T cell responses specific for several CHIKV proteins as shown by IFN- $\gamma$ ELISPOT analysis. The magnitude of antigen-specific T-cell responses in adult animals was higher compared to aged animals. T-cells specific for nspl were highest in frequency for both adult and aged animals. The breadth of $\mathrm{T}$ cell responses to CHIKV proteins differed in adult compared to aged animals; adults responded well to nsp1, capsid, E2, and nsp3 while aged animals responded mainly to nsp1 and nsp4 [59]. The results from these and other studies suggest that aged animals mount reduced and delayed $\mathrm{T}$ cell responses compared to adult animals to CHIKV infection, which may be a contributing factor to increased persistence in aged animals.

\section{NHP Humoral Responses against CHIKV}

Human infection with CHIKV results in rapid seroconversion. Anti-CHIKV antibodies appear within the first week of infection, but can be detected as early as the day of symptoms onset [55,58]. IgM peaks at 2-3 dpi and can persist at low levels for weeks to months. IgG anti-CHIKV antibodies are detectable 10-13 days post-onset and remain detectable for years after infection [83]. Antibodies from convalescent patients, in vitro are highly neutralizing, and in vivo can protect mice against CHIKV infection when given both prophylactically and therapeutically [84]. Some of the earliest examples of detecting and measuring anti-CHIKV antibodies in NHPs are from Binn et al. in 1967, and Nakao et al. in 1973 [51,60]. Binn et al. reported that in sera collected from Japanese monkeys (Macaca fuscata) infected with either the CHIKV-Asian or African strain, neutralizing antibodies were present 30 dpi as determined by plaque-inhibition assays [51]. Nakao et al. utilized two forms of inactivated CHIKV, UV-inactivated or formalin treatment, to generate an antibody response in inoculated Japanese monkeys [60]. Animals were given three injections of inactivated virus at 0,2 , and 9 weeks. After the second inoculation neutralizing antibodies were present $(400,50 \%$ PRNT) in the sera of animals, followed by a dramatic increase after the third injection [60]. UV-inactivated CHIKV was a far superior inducer of antibodies than the formalin treated CHIKV.

In the limited number of studies that have investigated NHP antibody response to CHIKV, the kinetics of the antibody response was similar to what has been described for humans. Anti-CHIKV antibodies in serum samples from CHIKV-LR infected cynomolgus macaques were detectable at 9 dpi. At this early time point $90 \%$ of the response was made up of the IgM isotype. By 16 dpi the IgM antibody response was replaced by $\operatorname{IgG}$ [78]. At later times post infection (100 and $180 \mathrm{dpi}$ ), IgG antibodies remained detectable (Table 1) [78].

Comparable antibody response kinetics was reported for rhesus macaques infected with CHIKV-LR and CHIKV-37997. In this model, anti-CHIKV IgG end point titers were compared in aged and adult animals using ELISA plates coated in either purified virions or cellular lysates from infected cells. For CHIKV-LR and CHIKV-37997 infected adult and aged animals, anti-CHIKV antibodies peaked near 21 dpi. The antibody kinetics were similar between the two age groups, but aged animals had significantly reduced IgG levels against virions [59]. Furthermore, when cellular lysates were used as a coating antigen, instead of purified virions, anti-CHIKV levels increased until $35 \mathrm{dpi}$, with similar levels reported for both adult and aged CHIKV-LR or CHIKV-37997 infected animals [59]. In pregnant rhesus macaques, anti-CHIKV antibodies were detectable at $7 \mathrm{dpi}$ and continued to rise until $21 \mathrm{dpi}$ [42]. The 
antibodies were highly neutralizing at 14 and 21 dpi for pregnant rhesus macaques infected with CHIKV-DHS-4263 compared to animals infected with CHIKV-37997 [42].

CHIKV-LR or CHIKV-37997 infection induces robust proliferation of memory B cell subsets that precedes the detection of IgG in adult rhesus macaques. As described for T cells, B cell proliferation in aged animals was also delayed and decreased [59]. MZ-like B-cell proliferation was detected at $10 \mathrm{dpi}$, peaked at $14 \mathrm{dpi}$, and returned to baseline by $21 \mathrm{dpi}$ in adult CHIKV-LR infected rhesus macaques. Compared to adult animals, proliferation of MZ-like B-cells in aged animals was delayed. Proliferation of memory B-cells in adult rhesus-macaques infected with either CHIKV-LR or 37997 was biphasic; two peaks in proliferation occurred at 14 dpi and 28 dpi [59]. In aged animals, proliferation of memory B-cells was decreased and the second peak at 28 dpi was absent. The lack of this second peak could be due to the waning immune response caused by age [59].

Both NHPs and humans develop similar CHIKV antibody epitope recognition after CHIKV infection. The N-terminal region of the E2 glycoprotein was highly recognized by anti-CHIKV antibodies from CHIKV-LR infected cynomolgus macaques. Antibodies recognizing the same region from human patients infected with CHIKV has been found to provide a long-lasting protective response during the whole course of disease $[85,86]$. The specific E2 epitope recognized by human antibodies is called E2EP3 (amino acids 2800-2818) [86,87]. The same E2EP3 region is recognized by anti-CHIKV antibodies in sera of CHIKV-infected macaques up to 100 dpi [78]. There was only one other common E2 epitope identified by antibodies from both patients and cynomolgus macaques (amino acids 30253058) $[78,85,86]$. Anti-E2EP3 antibodies from infected cynomolgus macaques make up a large percentage of the antibody responses during the early stage of infection, which has also been shown for humans $[78,86]$. At later stages of disease, the convalescent and recovery phase, there is an equal distribution of the epitopes recognized by anti-CHIKV cynomolgus macaque antibodies including linear B-cell epitopes from E2, E3, capsid, nsp3, nsp1 and nsp4 proteins [78].

\subsection{Efficacy Testing of CHIKV Vaccines and Therapeutics in NHP}

\subsubsection{CHIKV Vaccine Trials in NHP}

A benefit to the NHP model is the ability to test the efficacy of vaccines and therapeutics in an outbred species while maintaining controls over experimental conditions. NHPs have been used as models to test the antibody producing potential of CHIKV treatments and vaccines [60,76]. Early studies showed that vaccination of Japanese Macaques with UV-inactivated or formalin treated CHIKV resulted in a neutralizing antibody response that could be enhanced by booster immunizations [60].

One of the early vaccines was a live-attenuated CHIKV 181/clone 25 derived from serial passaging the virus in MRC-5 cells [77]. Immunization of rhesus macaques resulted in low viremia and induced production of neutralizing antibodies by day 14. Immunized animals were protected from subsequent challenge, demonstrated by absence of virus in the serum. The vaccine progressed to phase II clinical trials but was halted because a small percentage of volunteers developed transient arthralgia [88].

Two live-attenuated CHIKV-IRES vaccine candidates, which contain a picornavirus internal ribosome entry site (IRES) to attenuate the virus, were recently tested in cynomolgus macaques [74]. A single vaccination with either CHIKV/IRES construct protected the cynomolgus macaques from 
viremia, fever, and rise in heart rate. At 35 dpi, virus titers were analyzed in axillary, bronchial, and inguinal lymph nodes and serum, and no virus was found. One limitation of the study was that they did not titer muscle, spleen, or liver tissues previously determined to be sites of persistence in the cynomolgus macaque model [53].

A CHIKV virus-like particle (VLP) vaccine protected rhesus macaques from CHIKV challenge [76]. Compared to control animals, VLP-vaccinated animals did not develop viremia, or show signs of acute CHIKV disease, demonstrating protection from infection. The VLP vaccine required at least two vaccinations for production of high titer neutralizing antibodies and passed phase 1 clinical trials [89]. The vaccines and therapeutics for CHIKV that have been tested in NHPs are listed in Table 2.

Table 2. CHIKV Vaccines and Therapeutics Tested in NHPs.

\begin{tabular}{|c|c|c|c|c|}
\hline Vaccine Type & $\begin{array}{c}\text { Number of } \\
\text { Vaccinations }\end{array}$ & $\begin{array}{c}\text { Immunogenicit } \\
\text { y Measured }\end{array}$ & $\begin{array}{c}\text { Challenge } \\
\text { Dose/Strain/Route }\end{array}$ & Reference \\
\hline $\begin{array}{c}\text { Formalin-inactivated/ } \\
\text { UV-inactivated }\end{array}$ & 3 & $\begin{array}{l}\text { Neutralizing } \\
\text { antibodies }\end{array}$ & Not reported & {$[60,90]$} \\
\hline Live-attenuated & 1 & $\begin{array}{l}\text { Neutralizing } \\
\text { antibodies }\end{array}$ & $\begin{array}{c}10^{5} \mathrm{PFU} / \mathrm{CHIKV}-15561 / \\
\text { i.m. }\end{array}$ & [77] \\
\hline Virus-Like Particle (VLP) & 3 & $\begin{array}{l}\text { Neutralizing } \\
\text { antibodies }\end{array}$ & $\begin{array}{c}10^{10} \mathrm{PFU} / \mathrm{CHIKV}-\mathrm{LR} / \\
\text { i.v. }\end{array}$ & [76] \\
\hline DNA & 5 & $\begin{array}{l}\text { Neutralizing } \\
\text { antibodies / T } \\
\text { cells }\end{array}$ & Not reported & [91] \\
\hline CHIKV/IRES & 1 & $\begin{array}{c}\text { Neutralizing } \\
\text { antibodies }\end{array}$ & $\begin{array}{l}10^{5} \mathrm{PFU} / \mathrm{CHIKV-LR} \mathrm{/} \\
\text { s.c. }\end{array}$ & [74] \\
\hline Therapeutic Type & $\begin{array}{c}\text { Infection } \\
\text { Dose/Strain/Route }\end{array}$ & $\begin{array}{c}\text { Therapeutic } \\
\text { Delivery }\end{array}$ & Measure of Protection & \\
\hline Antibody Therapeutic & $\begin{array}{l}10^{7} \mathrm{PFU} / \text { CHIKV-LR } \\
\text { / s.c. }\end{array}$ & $1 \& 3$ dpi / i.v. & Virus dissemination & [63] \\
\hline
\end{tabular}

\subsubsection{CHIKV Antiviral Therapeutic Trials in NHP}

Immunotherapeutics have also been tested in rhesus macaques as prophylactic treatment options for CHIKV infections. Two humanized monoclonal antibodies (mAb CHK-152 and CHK-166) that recognize epitopes within the structural EI and E2 proteins, previously shown to be protective as a prophylactic treatment in Ifnar ${ }^{-/-}$mice [75], were tested in combination as a post-exposure therapeutic for CHIKV in rhesus macaques [63]. In this study, rhesus macaques were infected subcutaneously in both arms with a total of $10^{7} \mathrm{pfu}$ CHIKV-LR distributed over 10 sites. Then at 1 and 3 dpi the animals were intravenously infused into the saphenous vein with either a cocktail of anti-CHIKV mAbs CHK-152 and CHK-166 or a control mAb (WNV E16). Although both groups had detectable CHIKV in the serum at 1 dpi, no virus was detected in serum at 2 dpi of animals that received CHIKV mAb therapy. At 7 dpi viral RNA load and tissue dissemination was quantified. Viral burden was similar in the arm muscles, joints and axillary lymph nodes between the anti-CHIKV mAb treated group and the control group. However, viral burdens in the joints and tissues of the legs, as well as the inguinal lymph node that drains the leg were reduced in the animals that received the anti-CHIKV mAb compared to controls. 
Measurement of viral burdens in other organs revealed that virus levels were also reduced in the kidney, lungs, and mesenteric lymph nodes in animals treated the anti-CHIKV mAb. In contrast there was no difference in the viral burden in the heart and spleen between the two study groups.

These results have generated interesting mechanisms about how CHIKV disseminates from the initial point of infection in NHPs. From this study, we speculate that CHIKV travels from the arm (the infection site) into the draining axillary lymph nodes where it then causes widespread viremia in the blood. Once in the blood the virus quickly infects the spleen and heart. Then it establishes infection in the distal joints and muscles, their draining lymph nodes as well as the secondary organs like the lungs and kidneys. However, animals that received antibody therapy were much more limited in their level of viral dissemination to the distal joints, muscles, and secondary organs. The ability to accurately detect blockage of viremia, as well as CHIKV dissemination to tissues away from the site of infection in an animal model, as was demonstrated in this study, makes rhesus macaques an ideal preclinical model for testing therapeutics [63].

\section{Conclusions}

Experimental infection of cynomolgus or rhesus macaques with CHIKV provide models that recapitulate many of the key features of human CHIKV infection. The acute stage of infection in both macaque models is characterized by the development of viremia, fever, rash, increase in cytokines and chemokines, and leukopenia. CHIKV replicates locally at the site of infection and quickly disseminates to tissues where it replicates robustly, especially spleen, muscle, and joints (Table 1). The early convalescent stage of infection is marked by a return of leukocyte numbers in the blood to normal, along with infiltration of infected macrophages along with virus into lymphoid organs and joints, as shown in the cynomolgus macaque infection model. During the convalescent stage of infection, the rhesus macaque model was key in defining the kinetics of the adaptive immune response against CHIKV. Cynomolgus macaques show viral persistence, which has been the most difficult aspect of CHIKV infection to model in small animals. Infectious virus was isolated from infected animals up to 2 months post infection in lymphoid organs and liver. In these tissues, CHIKV was detected in activated macrophages, providing further insight into the nature of CHIKV persistence [53]. The similarities between CHIKV infections of NHPs and humans make NHPs an ideal model to not only study the immune response to $\mathrm{CHIKV}$, but also to evaluate the potential of anti-viral treatments and vaccines.

\section{Acknowledgments}

This work was supported by an ONPRC Core Support Pilot Project grant to IM and DNS and NIH grants (U54 AI081680, projects NO-001 \& DP-007 and U19 AI109680-01 to DNS).

\section{Author Contributions}

This review was conceived and written by all of the authors. 


\section{Conflicts of Interest}

The authors declare no conflict of interest.

\section{References}

1. Forrester, N.L.; Palacios, G.; Tesh, R.B.; Savji, N.; Guzman, H.; Sherman, M.; Weaver, S.C.; Lipkin, W.I. Genome-scale phylogeny of the alphavirus genus suggests a marine origin. J. Virol. 2012, 86, 2729-2738.

2. Powers, A.M.; Brault, A.C.; Shirako, Y.; Strauss, E.G.; Kang, W.; Strauss, J.H.; Weaver, S.C. Evolutionary relationships and systematics of the alphaviruses. J. Virol. 2001, 75, 10118-10131.

3. Powers, A.M.; Logue, C.H. Changing patterns of chikungunya virus: Re-emergence of a zoonotic arbovirus. J. Gen. Virol. 2007, 88, 2363-2377.

4. Sergon, K.; Njuguna, C.; Kalani, R.; Ofula, V.; Onyango, C.; Konongoi, L.S.; Bedno, S.; Burke, H.; Dumilla, A.M.; Konde, J.; et al. Seroprevalence of chikungunya virus (chikv) infection on lamu island, kenya, october 2004. Am. J. Trop .Med. Hyg. 2008, 78, 333-337.

5. Sergon, K.; Yahaya, A.A.; Brown, J.; Bedja, S.A.; Mlindasse, M.; Agata, N.; Allaranger, Y.; Ball, M.D.; Powers, A.M.; Ofula, V.; et al. Seroprevalence of chikungunya virus infection on grande comore island, union of the comoros, 2005. Am. J. Trop. Med. Hyg. 2007, 76, 1189-1193.

6. Gerardin, P.; Guernier, V.; Perrau, J.; Fianu, A.; Le Roux, K.; Grivard, P.; Michault, A.; de Lamballerie, X.; Flahault, A.; Favier, F. Estimating chikungunya prevalence in la reunion island outbreak by serosurveys: Two methods for two critical times of the epidemic. BMC Infect. Dis. 2008, doi:10.1186/1471-2334-8-99.

7. Mowatt, L.; Jackson, S.T. Chikungunya in the caribbean: An epidemic in the making. Infect. Dis. Ther. 2014, 3, 63-68.

8. Weaver, S.C. Arrival of chikungunya virus in the new world: Prospects for spread and impact on public health. PLoS Negl. Trop. Dis. 2014, 8, e2921.

9. Weaver, S.C.; Forrester, N.L. Chikungunya: Evolutionary history and recent epidemic spread. Antiviral. Res. 2015, 120, 32-39.

10. Centers for Disease Control and Prevention. Nowcast: Chikungunya in the americas. Available online: http://www.cdc.gov/chikungunya/modeling/index.html (accessed on 9 September 2015).

11. Solignat, M.; Gay, B.; Higgs, S.; Briant, L.; Devaux, C. Replication cycle of chikungunya: A re-emerging arbovirus. Virology 2009, 393, 183-197.

12. Voss, J.E.; Vaney, M.C.; Duquerroy, S.; Vonrhein, C.; Girard-Blanc, C.; Crublet, E.; Thompson, A.; Bricogne, G.; Rey, F.A. Glycoprotein organization of chikungunya virus particles revealed by X-ray crystallography. Nature 2010, 468, 709-712.

13. Van Duijl-Richter, M.K.; Hoornweg, T.E.; Rodenhuis-Zybert, I.A.; Smit, J.M. Early events in chikungunya virus infection-from virus cellbinding to membrane fusion. Viruses 2015, 7, 3647-3674.

14. Strauss, J.H.; Strauss, E.G. The alphaviruses: Gene expression, replication, and evolution. Microbiol. Rev. 1994, 58, 491-562.

15. Melancon, P.; Garoff, H. Processing of the semliki forest virus structural polyprotein: Role of the capsid protease. J. Virol. 1987, 61, 1301-1309. 
16. Thomas, S.; Rai, J.; John, L.; Gunther, S.; Drosten, C.; Putzer, B.M.; Schaefer, S. Functional dissection of the alphavirus capsid protease: Sequence requirements for activity. J. Virol. 2010, doi:10.1186/1743-422X-7-327.

17. Garoff, H.; Sjoberg, M.; Cheng, R.H. Budding of alphaviruses. Virus. Res. 2004, 106, 103-116.

18. Jose, J.; Przybyla, L.; Edwards, T.J.; Perera, R.; Burgner, J.W., II; Kuhn, R.J. Interactions of the cytoplasmic domain of sindbis virus e2 with nucleocapsid cores promote alphavirus budding. J. Virol. 2012, 86, 2585-2599.

19. Simon, F.; Parola, P.; Grandadam, M.; Fourcade, S.; Oliver, M.; Brouqui, P.; Hance, P.; Kraemer, P.; Ali Mohamed, A.; de Lamballerie, X.; et al. Chikungunya infection: An emerging rheumatism among travelers returned from indian ocean islands. Report of 47 cases. Medicine 2007, 86, 123-137.

20. Dupuis-Maguiraga, L.; Noret, M.; Brun, S.; Le Grand, R.; Gras, G.; Roques, P. Chikungunya disease: Infection-associated markers from the acute to the chronic phase of arbovirus-induced arthralgia. PLoS Negl. Trop. Dis. 2012, 6, e1446.

21. Chow, A.; Her, Z.; Ong, E.K.; Chen, J.M.; Dimatatac, F.; Kwek, D.J.; Barkham, T.; Yang, H.; Rénia, L.; Leo, Y.S.; et al. Persistent arthralgia induced by chikungunya virus infection is associated with interleukin-6 and granulocyte macrophage colony-stimulating factor. J. Infect. Dis. 2011, 203, $149-157$.

22. Hoarau, J.J.; Jaffar Bandjee, M.C.; Krejbich Trotot, P.; Das, T.; Li-Pat-Yuen, G.; Dassa, B.; Denizot, M.; Guichard, E.; Ribera, A.; Henni, T.; et al. Persistent chronic inflammation and infection by chikungunya arthritogenic alphavirus in spite of a robust host immune response. J. Immunol. 2010, 184, 5914-5927.

23. Borgherini, G.; Poubeau, P.; Jossaume, A.; Gouix, A.; Cotte, L.; Michault, A.; Arvin-Berod, C.; Paganin, F. Persistent arthralgia associated with chikungunya virus: A study of 88 adult patients on reunion island. Clin. Infect. Dis. 2008, 47, 469-475.

24. Sissoko, D.; Malvy, D.; Ezzedine, K.; Renault, P.; Moscetti, F.; Ledrans, M.; Pierre, V. Post-epidemic chikungunya disease on reunion island: Course of rheumatic manifestations and associated factors over a 15-month period. PLoS Negl. Trop. Dis. 2009, 3, e389.

25. Schilte, C.; Staikowsky, F.; Staikovsky, F.; Couderc, T.; Madec, Y.; Carpentier, F.; Kassab, S.; Albert, M.L.; Lecuit, M.; Michault, A. Chikungunya virus-associated long-term arthralgia: A 36-month prospective longitudinal study. PLoS Negl. Trop. Dis. 2013, 7, e2137.

26. Economopoulou, A.; Dominguez, M.; Helynck, B.; Sissoko, D.; Wichmann, O.; Quenel, P.; Germonneau, P.; Quatresous, I. Atypical chikungunya virus infections: Clinical manifestations, mortality and risk factors for severe disease during the 2005-2006 outbreak on reunion. Epidemiol. Infect. 2009, 137, 534-541.

27. Rajapakse, S.; Rodrigo, C.; Rajapakse, A. Atypical manifestations of chikungunya infection. Trans. R. Soc. Trop. Med. Hyg. 2010, 104, 89-96.

28. Kee, A.C.; Yang, S.; Tambyah, P. Atypical chikungunya virus infections in immunocompromised patients. Emerg. Infect. Dis. 2010, 16, 1038-1040.

29. Ramful, D.; Carbonnier, M.; Pasquet, M.; Bouhmani, B.; Ghazouani, J.; Noormahomed, T.; Beullier, G.; Attali, T.; Samperiz, S.; Fourmaintraux, A.; et al. Mother-to-child transmission of chikungunya virus infection. Pediatr. Infect. Dis. J. 2007, 26, 811-815. 
30. Laras, K.; Sukri, N.C.; Larasati, R.P.; Bangs, M.J.; Kosim, R.; Djauzi; Wandra, T.; Master, J.; Kosasih, H.; Hartati, S.; et al. Tracking the re-emergence of epidemic chikungunya virus in indonesia. Trans. R. Soc. Trop. Med. Hyg. 2005, 99, 128-141.

31. Diallo, D.; Diagne, C.T.; Hanley, K.A.; Sall, A.A.; Buenemann, M.; Ba, Y.; Dia, I.; Weaver, S.C.; Diallo, M. Larval ecology of mosquitoes in sylvatic arbovirus foci in southeastern senegal. Parasit. Vectors 2012, doi:10.1186/1756-3305-5-286 286.

32. Diallo, D.; Chen, R.; Diagne, C.T.; Ba, Y.; Dia, I.; Sall, A.A.; Weaver, S.C.; Diallo, M. Bloodfeeding patterns of sylvatic arbovirus vectors in southeastern senegal. Trans. R. Soc. Trop. Med. Hyg. 2013, 107, 200-203.

33. Jupp, P.G.; McIntosh, B.M. Aedes furcifer and other mosquitoes as vectors of chikungunya virus at mica, northeastern transvaal, south africa. J. Am. Mosq. Control. Assoc. 1990, 6, 415-420.

34. Diallo, M.; Thonnon, J.; Traore-Lamizana, M.; Fontenille, D. Vectors of chikungunya virus in senegal: Current data and transmission cycles. Am. J. Trop. Med. Hyg. 1999, 60, 281-286.

35. Apandi, Y.; Nazni, W.A.; Noor Asleen, Z.A.; Vythilingam, I.; Noorazian, M.Y.; Azahari, A.H.; Zainah, S.; Lee, H.L. The first isolation of chikungunya virus from non-human primates in malaysia. J. Gen. Mol. Virol. 2009, 1, 35-39.

36. Inoue, S.; Morita, K.; Matias, R.R.; Tuplano, J.V.; Resuello, R.R.; Candelario, J.R.; Cruz, D.J.; Mapua, C.A.; Hasebe, F.; Igarashi, A.; et al. Distribution of three arbovirus antibodies among monkeys (macaca fascicularis) in the philippines. J. Med. Primatol. 2003, 32, 89-94.

37. Marchette, N.J.; Rudnick, A.; Garcia, R.; MacVean, D.W. Alphaviruses in peninusular malaysia: I. Virus isolations and animal serology. Se. Asian. J. Trop. Med. 1978, 9, 317-329.

38. Volk, S.M.; Chen, R.; Tsetsarkin, K.A.; Adams, A.P.; Garcia, T.I.; Sall, A.A.; Nasar, F.; Schuh, A.J.; Holmes, E.C.; Higgs, S.; et al. Genome-scale phylogenetic analyses of chikungunya virus reveal independent emergences of recent epidemics and various evolutionary rates. J. Virol. 2010, $84,6497-6504$.

39. Schuffenecker, I.; Iteman, I.; Michault, A.; Murri, S.; Frangeul, L.; Vaney, M.C.; Lavenir, R.; Pardigon, N.; Reynes, J.M.; Pettinelli, F.; et al. Genome microevolution of chikungunya viruses causing the indian ocean outbreak. PLoS Med. 2006, 3, e263.

40. Tsetsarkin, K.A.; Vanlandingham, D.L.; McGee, C.E.; Higgs, S. A single mutation in chikungunya virus affects vector specificity and epidemic potential. PLoS Pathog. 2007, 3, e201.

41. Vazeille, M.; Moutailler, S.; Coudrier, D.; Rousseaux, C.; Khun, H.; Huerre, M.; Thiria, J.; Dehecq, J.S.; Fontenille, D.; Schuffenecker, I.; et al. Two chikungunya isolates from the outbreak of la reunion (indian ocean) exhibit different patterns of infection in the mosquito, Aedes albopictus. PLoS ONE 2007, 2, e1168.

42. Chen, C.I.; Clark, D.C.; Pesavento, P.; Lerche, N.W.; Luciw, P.A.; Reisen, W.K.; Brault, A.C. Comparative pathogenesis of epidemic and enzootic chikungunya viruses in a pregnant rhesus macaque model. Am. J. Trop. Med. Hyg. 2010, 83, 1249-1258.

43. Leparc-Goffart, I.; Nougairede, A.; Cassadou, S.; Prat, C.; de Lamballerie, X. Chikungunya in the americas. Lancet 2014, 383, 514.

44. Couderc, T.; Chretien, F.; Schilte, C.; Disson, O.; Brigitte, M.; Guivel-Benhassine, F.; Touret, Y.; Barau, G.; Cayet, N.; Schuffenecker, I.; et al. A mouse model for chikungunya: Young age and inefficient type-i interferon signaling are risk factors for severe disease. PLoS Pathog. 2008, 4, e29. 
45. Hawman, D.W.; Stoermer, K.A.; Montgomery, S.A.; Pal, P.; Oko, L.; Diamond, M.S.; Morrison, T.E. Chronic joint disease caused by persistent chikungunya virus infection is controlled by the adaptive immune response. J. Virol. 2013, 87, 13878-13888.

46. Poo, Y.S.; Rudd, P.A.; Gardner, J.; Wilson, J.A.; Larcher, T.; Colle, M.A.; Le, T.T.; Nakaya, H.I.; Warrilow, D.; Allcock, R.; et al. Multiple immune factors are involved in controlling acute and chronic chikungunya virus infection. PLoS Negl. Trop. Dis. 2014, 8, e3354.

47. Teo, T.H.; Lum, F.M.; Claser, C.; Lulla, V.; Lulla, A.; Merits, A.; Renia, L.; Ng, L.F. A pathogenic role for $\mathrm{cd}^{4+} \mathrm{t}$ cells during chikungunya virus infection in mice. J. Immunol. 2013, 190, 259-269.

48. Morrison, T.E.; Oko, L.; Montgomery, S.A.; Whitmore, A.C.; Lotstein, A.R.; Gunn, B.M.; Elmore, S.A.; Heise, M.T. A mouse model of chikungunya virus-induced musculoskeletal inflammatory disease: Evidence of arthritis, tenosynovitis, myositis, and persistence. Am. J. Pathol. 2011, 178, 32-40.

49. Gardner, J.; Anraku, I.; Le, T.T.; Larcher, T.; Major, L.; Roques, P.; Schroder, W.A.; Higgs, S.; Suhrbier, A. Chikungunya virus arthritis in adult wild-type mice. J .Virol. 2010, 84, 8021-8032.

50. Ross, R.W. The newala epidemic. Iii. The virus: Isolation, pathogenic properties and relationship to the epidemic. J. Hyg. (Lond) 1956, 54, 177-191.

51. Binn, L.N.; Harrison, V.R.; Randall, R. Patterns of viremia and antibody observed in rhesus monkeys inoculated with chikungunya and other serologically related group a arboviruses. Am. J. Trop. Med. Hyg. 1967, 16, 782-785.

52. Messaoudi, I.; Vomaske, J.; Totonchy, T.; Kreklywich, C.N.; Haberthur, K.; Springgay, L.; Brien, J.D.; Diamond, M.S.; Defilippis, V.R.; Streblow, D.N. Chikungunya virus infection results in higher and persistent viral replication in aged rhesus macaques due to defects in anti-viral immunity. PLoS Negl. Trop. Dis. 2013, 7, e2343.

53. Labadie, K.; Larcher, T.; Joubert, C.; Mannioui, A.; Delache, B.; Brochard, P.; Guigand, L.; Dubreil, L.; Lebon, P.; Verrier, B.; et al. Chikungunya disease in nonhuman primates involves long-term viral persistence in macrophages. J. Clin. Invest. 2010, 120, 894-906.

54. Charrel, R.N.; de Lamballerie, X.; Raoult, D. Chikungunya outbreaks - the globalization of vectorborne diseases. N. Engl. J. Med. 2007, 356, 769-771.

55. Lanciotti, R.S.; Kosoy, O.L.; Laven, J.J.; Panella, A.J.; Velez, J.O.; Lambert, A.J.; Campbell, G.L. Chikungunya virus in us travelers returning from india, 2006. Emerg. Infect. Dis. 2007, 13, 764-767.

56. Staples, J.E.; Breiman, R.F.; Powers, A.M. Chikungunya fever: An epidemiological review of a re-emerging infectious disease. Clin. Infect. Dis. 2009, 49, 942-948.

57. Laurent, P.; Le Roux, K.; Grivard, P.; Bertil, G.; Naze, F.; Picard, M.; Staikowsky, F.; Barau, G.; Schuffenecker, I.; Michault, A. Development of a sensitive real-time reverse transcriptase pcr assay with an internal control to detect and quantify chikungunya virus. Clin. Chem. 2007, 53, 1408-1414.

58. Panning, M.; Grywna, K.; van Esbroeck, M.; Emmerich, P.; Drosten, C. Chikungunya fever in travelers returning to europe from the indian ocean region, 2006. Emerg. Infect. Dis. 2008, 14, 416-422.

59. Messaoudi, I.; Vomaske, J.; Totonchy, T.; Kreklywich, C.N.; Haberthur, K.; Springgay, L.; Brien, J.D.; Diamond, M.S.; Defilippis, V.R.; Streblow, D.N. Chikungunya virus infection results in higher and persistent viral replication in aged rhesus macaques due to defects in anti-viral immunity. PLoS Negl. Trop. Dis. 2013, 7, e2343. 
60. Nakao, E.; Hotta, S. Immunogenicity of purified, inactivated chikungunya virus in monkeys. Bull. World Health Organ. 1973, 48, 559-562.

61. Harrison, V.R.; Binn, L.N.; Randall, R. Comparative immunogenicities of chikungunya vaccines prepared in avian and mammalian tissues. Am. J. Trop. Med. Hyg. 1967, 16, 786-791.

62. Choumet, V.; Attout, T.; Chartier, L.; Khun, H.; Sautereau, J.; Robbe-Vincent, A.; Brey, P.; Huerre, M.; Bain, O. Visualizing non infectious and infectious anopheles gambiae blood feedings in naive and saliva-immunized mice. PLoS ONE 2012, 7, e50464.

63. Pal, P.; Fox, J.M.; Hawman, D.W.; Huang, Y.J.; Messaoudi, I.; Kreklywich, C.; Denton, M.; Legasse, A.W.; Smith, P.P.; Johnson, S.; et al. Chikungunya viruses that escape monoclonal antibody therapy are clinically attenuated, stable, and not purified in mosquitoes. J. Virol. 2014, 88, 8213-8226.

64. Carey, D.E.; Myers, R.M.; DeRanitz, C.M.; Jadhav, M.; Reuben, R. The 1964 chikungunya epidemic at vellore, south india, including observations on concurrent dengue. Trans. R. Soc. Trop. Med. Hyg. 1969, 63, 434-445.

65. Chatterjee, S.N.; Chakravarti, S.K.; Mitra, A.C.; Sarkar, J.K. Virological investigation of cases with neurological complications during the outbreak of haemorrhagic fever in calcutta. J. Indian. Med. Assoc. 1965, 45, 314-316.

66. Jadhav, M.; Namboodripad, M.; Carman, R.H.; Carey, D.E.; Myers, R.M. Chikungunya disease in infants and children in vellore: A report of clinical and haematological features of virologically proved cases. Indian. J. Med. Res. 1965, 53, 764-776.

67. Nimmannitya, S.; Halstead, S.B.; Cohen, S.N.; Margiotta, M.R. Dengue and chikungunya virus infection in man in thailand, 1962-1964. I. Observations on hospitalized patients with hemorrhagic fever. Am. J. Trop. Med. Hyg. 1969, 18, 954-971.

68. Thiruvengadam, K.V.; Kalyanasundaram, V.; Rajgopal, J. Clinical and pathological studies on chikungunya fever in madras city. Indian J. Med. Res. 1965, 53, 729-744.

69. Lemant, J.; Boisson, V.; Winer, A.; Thibault, L.; Andre, H.; Tixier, F.; Lemercier, M.; Antok, E.; Cresta, M.P.; Grivard, P.; et al. Serious acute chikungunya virus infection requiring intensive care during the reunion island outbreak in 2005-2006. Crit. Care Med. 2008, 36, 2536-2541.

70. Robin, S.; Ramful, D.; Le Seach, F.; Jaffar-Bandjee, M.C.; Rigou, G.; Alessandri, J.L. Neurologic manifestations of pediatric chikungunya infection. J. Child. Neurol. 2008, 23, 1028-1035.

71. Tandale, B.V.; Sathe, P.S.; Arankalle, V.A.; Wadia, R.S.; Kulkarni, R.; Shah, S.V.; Shah, S.K.; Sheth, J.K.; Sudeep, A.B.; Tripathy, A.S.; et al. Systemic involvements and fatalities during chikungunya epidemic in India, 2006. J. Clin. Virol. 2009, 46, 145-149.

72. Das, T.; Jaffar-Bandjee, M.C.; Hoarau, J.J.; Krejbich Trotot, P.; Denizot, M.; Lee-Pat-Yuen, G.; Sahoo, R.; Guiraud, P.; Ramful, D.; Robin, S.; et al. Chikungunya fever: Cns infection and pathologies of a re-emerging arbovirus. Prog. Neurobiol. 2010, 91, 121-129.

73. Gérardin, P.; Barau, G.; Michault, A.; Bintner, M.; Randrianaivo, H.; Choker, G.; Lenglet, Y.; Touret, Y.; Bouveret, A.; Grivard, P.; et al. Multidisciplinary prospective study of mother-to-child chikungunya virus infections on the island of la réunion. PLoS Med. 2008, 5, e60.

74. Roy, C.J.; Adams, A.P.; Wang, E.; Plante, K.; Gorchakov, R.; Seymour, R.L.; Vinet-Oliphant, H.; Weaver, S.C. Chikungunya vaccine candidate is highly attenuated and protects nonhuman primates against telemetrically monitored disease following a single dose. J. Infect. Dis. 2014, 209, 1891-1899. 
75. Pal, P.; Dowd, K.A.; Brien, J.D.; Edeling, M.A.; Gorlatov, S.; Johnson, S.; Lee, I.; Akahata, W.; Nabel, G.J.; Richter, M.K.; et al. Development of a highly protective combination monoclonal antibody therapy against chikungunya virus. PLoS Pathog. 2013, 9, e1003312.

76. Akahata, W.; Yang, Z.Y.; Andersen, H.; Sun, S.; Holdaway, H.A.; Kong, W.P.; Lewis, M.G.; Higgs, S.; Rossmann, M.G.; Rao, S.; et al. A virus-like particle vaccine for epidemic chikungunya virus protects nonhuman primates against infection. Nat. Med. 2010, 16, 334-338.

77. Levitt, N.H.; Ramsburg, H.H.; Hasty, S.E.; Repik, P.M.; Cole, F.E.; Lupton, H.W. Development of an attenuated strain of chikungunya virus for use in vaccine production. Vaccine 1986, 4, 157-162.

78. Kam, Y.W.; Lee, W.W.; Simarmata, D.; Le Grand, R.; Tolou, H.; Merits, A.; Roques, P.; Ng, L.F. Unique epitopes recognized by antibodies induced in chikungunya virus-infected non-human primates: Implications for the study of immunopathology and vaccine development. PLoS ONE 2014, 9, e95647.

79. Streblow, D.N. Therapeutic administration of humanized monoclonal antibodies limit chikungunya virus dissemination in rhesus macaques. 2015, in press.

80. Ng, L.F.; Chow, A.; Sun, Y.J.; Kwek, D.J.; Lim, P.L.; Dimatatac, F.; Ng, L.C.; Ooi, E.E.; Choo, K.H.; Her, Z.; et al. Il-1beta, il-6, and rantes as biomarkers of chikungunya severity. PLoS ONE 2009, 4, e4261.

81. Wauquier, N.; Becquart, P.; Nkoghe, D.; Padilla, C.; Ndjoyi-Mbiguino, A.; Leroy, E.M. The acute phase of chikungunya virus infection in humans is associated with strong innate immunity and t cd 8 cell activation. J. Infect. Dis. 2011, 204, 115-123.

82. Teo, T.H.; Lum, F.M.; Claser, C.; Lulla, V.; Lulla, A.; Merits, A.; Rénia, L.; Ng, L.F. A pathogenic role for cd4+ t cells during chikungunya virus infection in mice. J. Immunol. 2013, 190, 259-269.

83. Petitdemange, C.; Wauquier, N.; Vieillard, V. Control of immunopathology during chikungunya virus infection. J. Allergy. Clin. Immunol. 2015, 135, 846-855.

84. Couderc, T.; Khandoudi, N.; Grandadam, M.; Visse, C.; Gangneux, N.; Bagot, S.; Prost, J.F.; Lecuit, M. Prophylaxis and therapy for chikungunya virus infection. J. Infect. Dis. 2009, 200, 516-523.

85. Kam, Y.W.; Lee, W.W.; Simarmata, D.; Harjanto, S.; Teng, T.S.; Tolou, H.; Chow, A.; Lin, R.T.; Leo, Y.S.; Renia, L.; et al. Longitudinal analysis of the human antibody response to chikungunya virus infection: Implications for serodiagnosis and vaccine development. J. Virol. 2012, 86, 13005-13015.

86. Kam, Y.W.; Lum, F.M.; Teo, T.H.; Lee, W.W.; Simarmata, D.; Harjanto, S.; Chua, C.L.; Chan, Y.F.; Wee, J.K.; Chow, A.; et al. Early neutralizing igg response to chikungunya virus in infected patients targets a dominant linear epitope on the e2 glycoprotein. EMBO Mol. Med. 2012, 4, 330-343.

87. Kam, Y.W.; Pok, K.Y.; Eng, K.E.; Tan, L.K.; Kaur, S.; Lee, W.W.; Leo, Y.S.; Ng, L.C.; Ng, L.F. Sero-prevalence and cross-reactivity of chikungunya virus specific anti-e2ep3 antibodies in arbovirus-infected patients. PLoS Negl. Trop. Dis. 2015, 9, e3445.

88. Edelman, R.; Tacket, C.O.; Wasserman, S.S.; Bodison, S.A.; Perry, J.G.; Mangiafico, J.A. Phase ii safety and immunogenicity study of live chikungunya virus vaccine tsi-gsd-218. Am. J. Trop. Med. Hyg. 2000, 62, 681-685.

89. Chang, L.J.; Dowd, K.A.; Mendoza, F.H.; Saunders, J.G.; Sitar, S.; Plummer, S.H.; Yamshchikov, G.; Sarwar, U.N.; Hu, Z.; Enama, M.E.; et al. Safety and tolerability of chikungunya virus-like particle vaccine in healthy adults: A phase 1 dose-escalation trial. Lancet 2014, 384, 2046-2052. 
90. Harrison, V.R.; Eckels, K.H.; Bartelloni, P.J.; Hampton, C. Production and evaluation of a formalin-killed chikungunya vaccine. J. Immunol. 1971, 107, 643-647.

91. Mallilankaraman, K.; Shedlock, D.J.; Bao, H.; Kawalekar, O.U.; Fagone, P.; Ramanathan, A.A.; Ferraro, B.; Stabenow, J.; Vijayachari, P.; Sundaram, S.G.; et al. A DNA vaccine against chikungunya virus is protective in mice and induces neutralizing antibodies in mice and nonhuman primates. PLoS Negl. Trop. Dis. 2011, 5, e928.

(C) 2015 by the authors; licensee MDPI, Basel, Switzerland. This article is an open access article distributed under the terms and conditions of the Creative Commons Attribution license (http://creativecommons.org/licenses/by/4.0/). 